UDK: $37.012: 311$

Prethodno saopštenje

Primljeno: 7.5.2018.

Revidirana verzija: 1.6.2018.

Odobreno za štampu: 4.6.2018.

\title{
STATISTIČKA ANALIZA REFLEKSIVNE PRAKSE U ŠKOLSKOM OKRUŽENJU
}

\author{
Jelena Osmanović ${ }^{1}$ \\ Univerzitet u Nišu, Filozofski fakultet u Nišu, Departman za pedagogiju
}

Apstrakt: Svim profesionalcima je potrebno da uče iz sopstvene prakse i iskustva. Nema kvalitetnog predavanja bez aktivnog angažovanja učenika, tako nema ni seminara stručnog usavršavanja koji mogu da unaprede rad nastavnika ukoliko se aktivno ne angažuju i nakon njega. U radu se razmatraju stavovi nastavnika o refleksivnoj praksi. Za potrebe ovog istaživanja korišćen je instrument skale procene Likertovog tipa autora (Chee Choy \& San Oo, 2012) sa statističkom analizom dve subskale instrumenta: Sagledavanje sopstvenog rada i Razumevanje učenja kao permanentnog procesa. U istaživanju je učestvovalo 305 nastavnika prvog i drugog ciklusa osnovnog obrazovanja. Istraživanje je pokazalo da nastavnici evaluiraju sopstveni rad i vrednuju učenje kao vid doživotnog obrazovanja.

Ključne reči: nastavnici, permanentno obrazovanje, refleksivna praksa, samovrednovanje.

\section{Uvod}

Učionica, kao mikro okruženje za razvijanje društvenih odnosa, od nastavnika iziskuje ne samo kvalitetno podučavanje već i razumevanje potreba učenika, porodičnog i društvenog konteksta. Savremena učionica treba nastavnika razvijene mentalne discipline koji preuzima odgovornost za suočavanje s dilemama, donosi odluke, rešava problem, razvija samosvest i filozofsko promišljanje kao odrednice etičkog i profesionalnog kodeksa ponašanja (Larivee, 2000; 2008). Refleksivno podučavanje je proces u kome nastavnik neprestano preispituje sopstvenu praksu, razmišlja o onome što u učionici čini, zašto to čini i kakve efekte njegov način podučavanja ima na izgradnju znanja učenika. Na refleksivno podučavanje možemo gledati kao na proces samoposmatranja i samoevaluacije, kritičkog preispitivanja.

\footnotetext{
${ }^{1}$ jelena.osmanović@filfak.ni.ac.rs
} 


\section{Refleksivnost u radu nastavnika}

Najvažniji elementi refleksivne prakse su: započinjanje procesa refleksije odgovaranjem na pitanja o različitim aspektima sopstvene prakse, vođenje dnevnika rada, davanje saveta, izvođenje akcionih istraživanja, snimanje časova i analiza, proučavanje naučne i stručne literature, prisećanje i analiziranje sopstvenih iskustava iz škole, diskutovanje sa učenicima (feedback), deljenje iskustva sa kolegama (Maksimović, 2012; Radulović, 2011).

Kada su već definisani elementi refleksivne prakse, postavlja se pitanje: Koje karakteristike definišu nastavnika refleksivnog praktičara? Možemo ih grupisati na sledeći način: tendencija ka kontinuiranom samoanaliziranju i samopraćenju, osetljivost za sagledavanje situacije iz različitih uglova, traganje za elementima dobre prakse, otvorenost za probu drugačijih načina rada od ustaljenih, otvorenost nastavnika da razmenjuju iskustava sa kolegama, spremnost da na licu mesta promene prethodno postavljeni plan u zavisnosti od načina na koji učenici reaguju tokom časa (Buđevac i sar., 2013; Radulovć, 2011).

Činjenica je da sva pedagoška istraživanja za cilj imaju unapređivanje vaspitno-obrazovne prakse. Specifičnosti refleksivne prakse mogu se istraživati posebnom vrstom istraživanja kao što su akciona istraživanja. Posredstvom akcionih istraživanja mogu se identifikovati problemi koje rešavaju sami nastavnici praktičari, a ne profesionalni istraživači. Akciona istraživanja, pre svega, polaze od potreba nastavnika praktičara, a ne od zamisli pojedinaca ili institucija van školskog konteksta (Banđur i Maksimović, 2013; Maksimović i Banđur, 2013; Maksimović, 2017).

Smatra se da je isključiva usmerenost samo na teorijsko znanje nedovoljna za potrebno prilagođavanje na složene uslove vaspitno-obrazovne prakse. U radu nastavnika često se nailazi na situacije u kojima ne mogu pomoći ni unapred naučeni odgovori, već su potrebne veštine inovativnosti, improvizacije i testiranja različitih strategija. Stoga je važno već tokom visokog obrazovanja pripremati studente na izazove s kojima će se suočiti kada završe studije (Glasser, 2005). Za ostvarivanje tako složenih zadataka visokoškolska nastava koja osposobljava nastavnike treba ih pripremati za transformaciju monološke nastave u dijalošku, u kojoj treba aktivno da učestvuju sve osobe odgovorne za kvalitet vaspitno-obrazovnog procesa. Nastavnicima od izuzetne pomoći mogu biti pedagozi. Zato se pedagozi i obrazuju u ovoj sferi, i uče kako pomoći nastavnicima refleksivnim praktičarima.

$\mathrm{Za}$ aktivno učenje se podrazumeva znati kako delotvorno učiti, stvoriti potrebu za celoživotnim obrazovanjem, i znati kritički misliti (Nikčević-Milković, 2004). Refleksivni pristup sopstvenoj praksi nužni je preduslov saznanja o tome šta zaista radimo, šta znamo, i u čemu bi trebalo još napredovati, kako na individualnom, tako i na društvenom planu. Priroda vaspitno-obrazovne prakse je takva da se svakodnevno javlja mnoštvo problema koji se moraju hitno rešavati u samom toku akcije. Praksa je vrlo promenljiva i nepredvidljiva, pa ono što radimo zahteva stalnu proveru. Upravo se praksa temelji na refleksiji, prepoznavanju i proveravanju vaspitnih stilova, hipoteza i iskustava u prošlim i sadašnjim situacijama. Refleksivni praktičar 
je aktivni pojedinac koji istražuje mogućnost rešavanja problema u praksi, i karakteriše ga refleksivna otvorenost koja se javlja u situacijama kada smo voljni da preispitamo vlastito mišljenje. Sve ovo nas dovodi do konstatacije da je vaspitno-obrazovna praksa, bez obzira na to koliko bila uverljiva i lepo zamišljena, konstantno podložna preispitivanju i poboljšavanju (Maksimović i Osmanović, 2016).

\section{Metodološka obrazovanost nastavnika refleksivnog praktičara}

Dugo se smatralo da naučna istraživanja podrazumevaju takav proces u kojem istraživači proučavaju vaspitno-obrazovnu praksu, ali izbegavaju sopstveno učešće u njoj. Kada bi se i uvele određene promene (npr. kroz akciona i eksperimentalna istraživanja), tada bi praktičari u najboljem slučaju bili zaduženi za unošenje eksperimentalnih činilaca (nezavisnih varijabli), prema strogo zadatim uputstvima profesionalnih istraživača. Premda su naučna istraživanja, posebno eksperimentalni pristup, iznedrila mnoštvo zanimljivih rezultata, uprkos tome što je istraživačka metodologija postala sve savršenija, stvara se predstava kako nauka i praksa nemaju puno toga zajedničkog, i da između njih postoji nepremostivi jaz (Cunningham, 1993; Fullan, 1993).
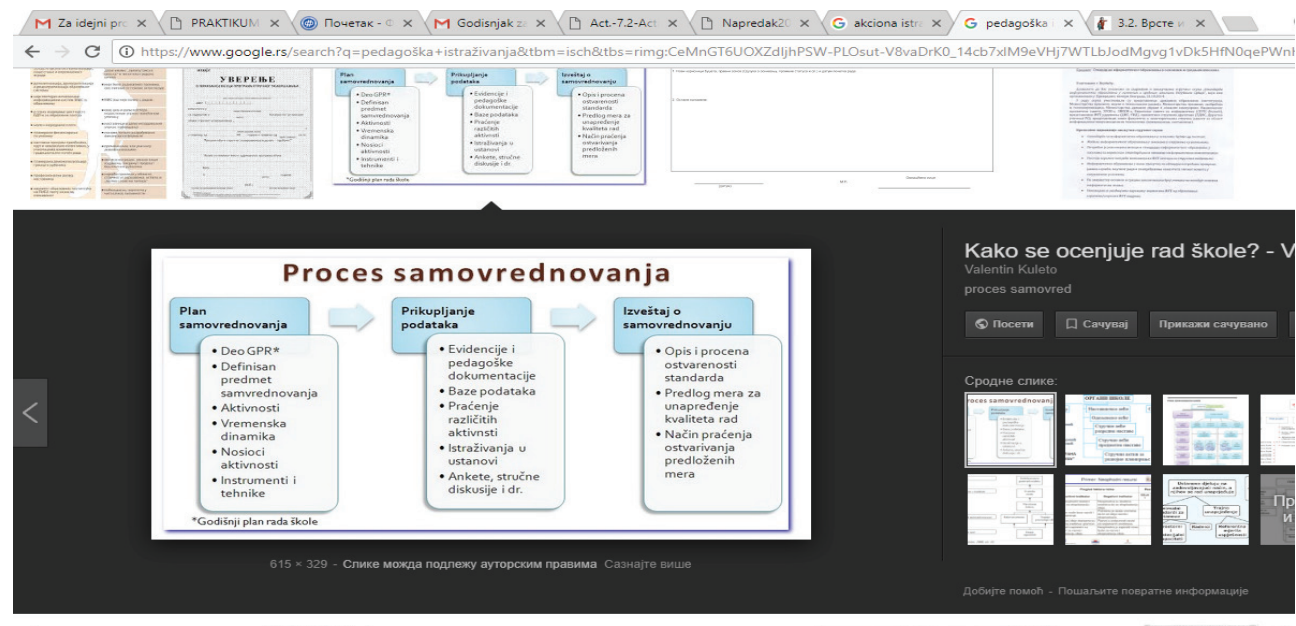

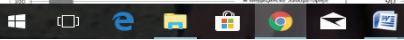

Slika 1. Metodologija u samovrednovanju (prema Kuleto, 2015)

Slika 1 pokazuje da je proces samovrednovanja u školama izuzetno metodološki utemeljen. Ako nešto vrednujemo i samovrednujemo moramo jasno naznačiti šta je predmet evaluacije, koje aktivnosti evaluiramo, koji su vremenski okviri, ko su nosioci aktivnosti, tj. ko čini uzorak, koje metode, tehnike i instrumente treba koristiti. Potom sledi prikupljanje podataka, a nakon toga izveštaj o samovrednovanju. Slika opisuje šta se od jednog nastavnika zapravo očekuje, a to je da poznaje tri krucijalne 
etape sprovođenja pedagoških istraživanja: pripremna etapa, etapa sprovođenja, i etapa analize i interpretacije rezultata istraživanja. Za jednog savremenog nastavnika poznavanje metodologije pedagoških istraživanja, neće samo olakšati procese evaluacije i samoevaluacije u školi, već je to korak ka jačanju sebe kao istraživača. Poznavanje ovih etapa može im omogućiti da sprovode mala, mikroistraživanja, eksperimentalna istraživanja i akciona istraživanja koja su karakteristična za školsko okruženje.

Kako je za refleksivnog praktičara karakteristično da svoja iskustva deli sa kolegama, u slučaju bilo kakvih nedoumica, on se može i treba konsultovati i sa stručnom službom, pedagogom škole, koji će mu sve nedoumice otkloniti i pomoći mu u realizaciji istraživanja. Ako je nastavnik spreman na takav način rada, kritički preispituje sebe i rezultate do kojih je došao, radi na sebi i stručno se obrazuje i usavršava za dalje inovativnosti u svom radu, možemo ga okarakterisati kao refleksivnog praktičara.

\section{Metodologija istraživanja}

Istraživanjem se želelo utvrditi da li se nastavnici osnovnih škola prepoznaju kao nastavnici refleksivni praktičari. Poseban osvrt bio je na istraživanju dve komponente reflekivne prakse, odnosno samoevaluacije nastavnika i njihove percepcije učenja kao važne karike permanentnog obrazovanja. U istraživanju je učestvovalo 305 nastavnika osnovnih škola Nišavskog okruga. Za potrebe ovog istraživanja korišćen je baždareni instrument (Chee Choy \& San Oo, 2012). Za potrebe ovog istraživanja statističkom analizom obrađene su dve subskale originalnog istrumenta (Samoevaluacije i Permanentno obrazovanje). U radu je, u skladu sa prirodom istraživanja implementirana jedna nezavisna varijabla, a to je ciklus obrazovanja sa kategorijama učitelj-nastavnik.

\section{Rezultati istraživanja}

Refleksivni praktičar je onaj praktičar koji svoje delovanje zasniva na istraživanju i kritičkom promišljanju sopstvenog delovanja, koji sagledava praksu iz različitih perspektiva, zasniva je polazeći od otkrivanja i razumevanja sopstvenih pretpostavki, koji razvija i menja svoju praksu i okolnosti koje su za nju značajne (Buđevac i sar., 2013).

Tabela 1. Refleksije nastavnika o samoevaluaciji sopstvnog rada

\begin{tabular}{lcccc}
\hline & Minimum & Maximum & M & SD \\
\hline $\begin{array}{l}\text { Uvek razmišljam o onome šta } \\
\text { radim na časovima kako bih } \\
\text { se unapredio }\end{array}$ & 2.00 & 5.00 & 4.55 & 0.66 \\
$\begin{array}{l}\text { Trudim se da pratim } \\
\text { naređenja pre nego da budem } \\
\text { inovativan, jer ne bih želo da } \\
\text { upadnem u nevolju }\end{array}$ & 1.00 & 5.00 & 3.20 & 1.23
\end{tabular}


Trudim se da razmišljam o onome što predajem svojim učenicima iz moje oblasti 1.00 5.00 4.66 0.63 kako bih poboljšao svoja predavanja

Refleksija u nastavi predstavlja način da postanemo svesni toga kako se odvija proces nastave koji vodimo. To je metod samoevaluacije. Istraživanje je pokazalo da nastavnici razmišljaju o sopstvenom radu, razmišljaju o onome što predaju svojim učenicima na časovima i teže da ih unaprede, $\mathrm{M}>4.00$ (slažem se na skali procene).

Tabela 2. Razlike u stavovima nastavnika/učitelja u sagledavanju svog rada s obzirom na ciklus obrazovanja.

\begin{tabular}{|c|c|c|c|c|c|c|c|}
\hline & $\begin{array}{c}\text { Ciklus } \\
\text { obrazovanja }\end{array}$ & $\mathrm{N}$ & M & $\mathrm{sd}$ & $\mathrm{t}$ test & $\mathrm{df}$ & sig \\
\hline \multirow{2}{*}{$\begin{array}{l}\text { Uvek razmišljam o onome šta radim na } \\
\text { časovima, kako bih se unapredio. }\end{array}$} & Učitelj & 158 & 4.51 & 0.7 & \multirow{2}{*}{-1.22} & \multirow{2}{*}{303} & \multirow{2}{*}{0.23} \\
\hline & Nastavnik & 147 & 4.61 & 0.62 & & & \\
\hline \multirow{2}{*}{$\begin{array}{l}\text { Trudim se da pratim naređenja pre nego } \\
\text { da budem inovativan, jer ne bih želeo da } \\
\text { upadnem u nevolju. }\end{array}$} & Učitelj & 158 & 3.11 & 1.21 & \multirow{2}{*}{-1.41} & \multirow{2}{*}{303} & \multirow{2}{*}{0.16} \\
\hline & Nastavnik & 147 & 3.31 & 1.26 & & & \\
\hline \multirow{2}{*}{$\begin{array}{l}\text { Trudim se da razmišljam o onome } \\
\text { što predajem svojim učenicima iz } \\
\text { moje oblasti kako bih poboljšao svoje } \\
\text { predavanje. }\end{array}$} & Učitelj & 158 & 4.66 & 0.65 & \multirow[b]{2}{*}{-0.03} & \multirow[b]{2}{*}{303} & \multirow[b]{2}{*}{0.98} \\
\hline & Nastavnik & 147 & 4.67 & 0.61 & & & \\
\hline
\end{tabular}

$\mathrm{U}$ tabeli 2 prikazane su razlike u stavovima nastavnika u sagledavanju svog rada s obzirom na ciklus obrazovanja. Može se uočiti da ni na jednoj varijabli ne postoji statistički značajna razlika u stavovima nastavnika/učitelja u sagledavanju svog rada $\mathrm{s}$ obzirom na obrazovni ciklus, $\mathrm{p}>0.05$. Podatak pokazuje da postoji homogenost $u$ odgovorima učitelja i nastavnika, i da je jednako bitna i učiteljima i nastavnicima.

Tabela 3. Razumevanje učenja kao permanentnog procesa

\begin{tabular}{lcccc}
\hline & Minimum & Maximum & M & SD \\
\hline $\begin{array}{l}\text { Znam da to kako ću predstaviti svoj } \\
\text { predmet ima uticaja na doživljavanje } \\
\text { mog predmeta od strane učenika. }\end{array}$ & & & \\
$\begin{array}{l}\text { Svaki put kada se predstavljam } \\
\text { razredu moram biti svestan da mi je } \\
\text { potrebna refleksija o tome kako sam } \\
\text { izlagao ne bih li promenio nešto za }\end{array}$ & 2.00 & 5.00 & 4.35 & 0.67 \\
$\begin{array}{l}\text { sledeći put } \\
\text { Znam da imam svoje prednosti i } \\
\text { nedostatke i da je biti nastavnik }\end{array}$ & & & \\
$\begin{array}{l}\text { zahtevan posao. Moram stalno } \\
\text { da tragam za novim vidovima } \\
\text { unapređivanja kako bih poboljšao } \\
\text { svoje izlaganje }\end{array}$ & 1.00 & & & \\
\end{tabular}


Ja znam šta radim kao nastavnik

i ne provodim mnogo vremena

razmišljajući o poboljšanju sebe kao

1.00

5.00

2.51

1.21

nastavnika

Nastavnici, svaki put kada se predstavljaju svojim učenicima traže neku vrstu povratne informacije i refleksije učenika, o tome kakvo je bilo izlaganje nastavnika, i da li bi nešto trebalo promeniti naredni put. Istraživanje je pokazalo da su nastavnici svesni kompleksnosti svoje profesionalne uloge. Nastavnici stalno tragaju za novim vidovima načina izlaganja $\mathrm{M}>4.00$.

Tvrdnju negativne konotacije (da nastavnici ne provode mnogo vremena razmišljajući o poboljšanju sebe kao nastavnika) nastavnici su negativno ocenili $\mathrm{M}>2.00$. Tvrdnja pokazuje da nastavnici preispituju svoju ulogu, i kvalitet svog rada. Navedeni podatak pokazuje da su nastavnici refleksivni praktičari koji kritički preispituju sebe.

Tabela 4. Razlike u stavovima nastavnika/učitelja u razumevanju učenja kao permanentnog procesa u odnosu na ciklus obrazovanja

\begin{tabular}{|c|c|c|c|c|c|c|c|}
\hline & $\begin{array}{c}\text { Ciklus } \\
\text { obrazovanja }\end{array}$ & $\mathrm{N}$ & M & sd & $\mathrm{t}$ test & $\mathrm{df}$ & sig \\
\hline $\begin{array}{l}\text { Ja znam šta radim kao nastavnik } \\
\text { i ne provodim mnogo vremena } \\
\text { razmišljajući o poboljšanju sebe kao } \\
\text { nastavnika. }\end{array}$ & Nastavnik & 158 & 2.44 & 1.20 & -1.06 & 303 & 0.29 \\
\hline $\begin{array}{l}\text { Znam da imam svoje prednosti i } \\
\text { nedostatke i da biti nastavnik je } \\
\text { zahtevan posao. Moram stalno } \\
\text { da tragam za novim vidovima } \\
\text { unapređivanja kako bih poboljšao } \\
\text { svoje izlaganje. }\end{array}$ & Nastavnik & 147 & 4.31 & 0.75 & 0.39 & 303 & 0.70 \\
\hline $\begin{array}{l}\text { Znam da to kako ću predavati svoj } \\
\text { predmet ima uticaja na doživljavanje } \\
\text { mog predmeta od strane učenika. } \\
\text { Svaki put kada se predstavljam } \\
\text { razredu moram biti svestan da mi je } \\
\text { potrebna refleksija o tome kako sam } \\
\text { izlagao ne bih li promenio nešto za } \\
\text { sledeći put. }\end{array}$ & Nastavnik & 158 & 4.37 & 0.69 & 0.61 & 303 & 0.54 \\
\hline
\end{tabular}

U tabeli 4 prikazane su razlike u aritmetičkim sredinama stavova nastavnika/ učitelja o razumevanju učenja kao permanentnog procesa, s obzirom na ciklus obrazovanja. Primetno je da ni na jednoj varijabli ne postoji statistički značajna razlika u stavovima nastavnika i učitelja s obzirom na cikluis obrazovanja, $p>0,05$. Navedeni podaci pokazuju da je prisutna homogenost $\mathrm{u}$ odgovorima ispitanika, bez obzira da li su u pitanju učitelji ili nastavnici. 


\section{Zaključak}

$\mathrm{Na}$ času je nastavnik često u poziciji posmatrača i menja plan u skladu sa onim šta se dešava u učionici. Odluke moraju da se donesu brzo, da bi čas bio efikasan, a ishodi postignuti. U refleksivnoj praksi "svi su na dobitku". Pošto veće iskustvo ne znači automatski više znanja i veština, potrebno je promišljati sopstvenu praksu bez obzira na godine, kontinuirano analizirati svoju ulogu, stavove, vrednosti, postupke i odnose koje uspostavljaju sa učenicima. Time nastavnici mogu identifikovati svoje snage i slabosti, i da izvode zaključke o profesionalnim znanjima i veštinama koje žele da razviju. Nastavnici treba da poznaju sve aspekte refleksivne prakse kako bi o svakoj komponenti mogla biti vršena evaluacija. Predlaže se da se snaga refleksivnog kritičkog promišljanja još dublje istražuje i empirijski verifikuje, kako bi se produbila saznanja o delotvornim načinima sprovođenja refleksivne prakse. Koliko god je to aktuelna tema, čini se da je još uvek neistražena i da se mogu produbiti još više naša saznanja i otvoriti novi aspekti za istraživanje refleksivnosti nastavnika, koji će pomoći i nastavnicima istraživačima i nastavnicima praktičarima.

\section{Literatura}

Banđur, V. i Maksimović, J. (2013). The Teacher-A Reflective of the Teaching Practice. Croatian Journal of Education, 3(15), 99-124.

Buđevac, N., Jošić, S., Radišić, J., Baucal, A. (2013). Nastavnik kao refleksivni praktičar. Beograd: Priručnik za nastavnike.

Choy, S. C., \& Pou San, Oo. (2012). Reflective Thinking and Teaching Practices: A precursor for Incorporating critical thinking into the classroom? International Journal of Instruction, 5(1), 167-182.

Cunningham, B. (1993). Action Research and organizational development. Westport, CT: Praeger Publishers.

Glasser, W. (2005). Kvalitetna škola: Škola bez prisile. Zagreb: Educa.

Fullan, M. (1993). Change forces: Probing the depths od educational reform. London: Falmer.

Kuleto, V. (2015). Kako se ocenjuje rad škole. Preuzeto (15.4.2017.) sa http://www.valentinkuleto.com/2015/08/kako-se-ocenjuje-rad-skole/

Larrivee, B. (2000.). Transforming teaching practice: Becoming the critically reflective teacher. Reflective practice, 1(3), 293-307.

Larrivee, B. (2008). Development of a tool to assess teachers' level of reflective practice. Reflective practice, 9(3), 341-360.

Maksimović, J. (2012). Akciona istraživanja u pedagoškoj teoriji i praksi. Niš: Filozofski fakultet

Maksimović, J. i Banđur, V. (2013). Savremena akciona istraživanja i metodološko obrazovanje nastavnika refleksivnog praktičara. Teme, 595-610. 
Maksimović, J i Osmanović, J. (2016): Istraživanja pedagoga u školi: Primeri refleksivne prakse. Niš: Filozofski fakultet.

Maksimović, J. (2017). Akciona istraživanja i refleksivna praksa. Niš: Univerzitet u Nišu.

Ninčević-Milković, A. (2004). Aktivno učenje na visokoškolskoj razini. Život i škola, 12, $47-54$.

Radulović, L. (2011). Obrazovanje nastavnika za refleksivnu praksu. Beograd: Filozofski fakultet.

\title{
STATISTICAL ANALYSIS OF REFLEXIVE PRACTICE IN THE SCHOOL ENVIRONMENT
}

\begin{abstract}
Jelena Osmanović
University of Niš, Faculty of Philosophy in Niš, Department of Pedagogy

Abstract: All professionals need to learn from their own practice and experience. There is no quality lecture without active engagement of students, so there are no professional training seminars that can improve the work of teachers if they do not actively engage after the seminar. The paper discusses the attitude of teachers on reflexive practice. For the purposes of this research, the Likert-type author of the assessment tool (Chee Choy \& San Oo, 2012) was used with a statistical analysis of two subconses of the Self-Understanding and Understanding the learning process as a permanent process. 305 teachers of the first and second cycle of elementary education took part in the research. The research has shown that teachers evaluate their own work and value learning as a lifelong education.
\end{abstract}

Keywords: teachers, permanent education, reflexive practice, self-examining.

\section{Citiranje članka:}

Osmanović, J. (2018). Statistička analiza refleksivne prakse u školskom okruženju. Godišnjak za pedagogiju, 3(1), 69-76. 